\title{
A new emerging problem in pediatric emergency units: Synthetic cannabinoids
}

\author{
Nükhet Aladağ-Çiftdemir, İlay Yücel, Rıdvan Duran, Ülfet Vatansever-Özbek, Betül Acunaş \\ Department of Pediatrics, Trakya University Faculty of Medicine, Edirne, Turkey. \\ E-mail: nukhetaladag@yahoo.com \\ Received: 29th April 2016, Revised: 20th October 2016, Accepted: 28th November 2016
}

SUMMARY: Aladağ-Çiftdemir N, Yücel İ, Duran R, Vatansever-Özbek Ü, Acunaş B. A new emerging problem in pediatric emergency units: Synthetic cannabinoids. Turk J Pediatr 2016; 58: 492-497.

Synthetic cannabinoids or synthetic marijuana derivatives known as "Bonzai" in Turkey are addictive substances that affect the brain and have serious side effects. In recent years, the use of these substances has also been increasing in our country as well as all over the world. These substances present with various names and brands, the most common names in Turkey are "Bonzai" and "Jamaika". In this study, we aimed to evaluate the demographic and clinical findings of these patients. We retrospectively evaluated patients admitted to our pediatric emergency department between March 2013 and March 2015 due to the complaints developing after the use of "Bonzai" in terms of age, gender, admission date, complaint, clinical findings, laboratory findings, consuming method of the substance, additional substance use, observation durations, hospitalization status and mortality rates. The most common complaint was faintness and drowsiness. Changes in the state of consciousness, tachycardia, hypertension were the most common clinical findings. Most common consuming method of the drug was in the form of smoking. The rate of "Bonzai" use among adolescents is increasing every day. Physicians in emergency departments should be educated on this issue and it must be kept in mind that most of the patients admitted are with complaints related to changes in the cognitive state (of consciousness) but they can also apply with complaints about all other systems.

Key words: bonzai, bonzai abuse, pediatric emergency, synthetic cannabinoids.

Synthetic cannabinoids (SCs) or synthetic marijuana derivatives are known under the names of "Spice" in Europe, "K2", "Genie" in the United States of America", and "Bonzai" and "Jamaika" in Turkey, and are addictive substances that affect the brain and have serious side effects ${ }^{1,2}$. In recent years, the use of these substances has also been increasing in our country as well as all over the world. The reason why the use of SC has become so easily popular especially among the adolescents is that the name of "Bonzai" known by the users has created a false perception of its being harmless and as the content is continuously changed by the manufacturers, pharmacological profiles cannot be determined ${ }^{3}$. For the first time in Europe in 2004, it was put on sale over the internet and in private markets by statements like "harmless", "legal marijuana alternative" and "designer drugs"2,3. In Turkey, SC (JWH018) which has been imported illegally from foreign countries, was caught on in May in 2010 for the first time. Production of SCs in Turkey has not been determined yet ${ }^{1}$. The sale of these products is done in packages containing similar phrases like "Bath salts," "Plant fertilizer", "Not for human consumption". The most common names are "Bonzai Aromatic Potpourri" and "Bonzai Plant Growth Regulator"1,4. As there is an increasing number of cases applying to our pediatric emergency department every day, we aimed to evaluate the demographic and clinical findings of these patients.

\section{Materials and Methods}

Ten admissions of 9 patients to our pediatric emergency department at Trakya University 
Faculty of Medicine between March 2013 and March 2015 due to complaints that started after the use of "Bonzai" were analyzed retrospectively. There were 2 admissions of one patient with an interval of 1.5 months for the same reason. Patients were evaluated in terms of age, gender, complaints, clinical findings (physical, psychoactive and metabolic effects), laboratory tests (complete blood count, blood sugar levels, liver and kidney function tests, creatine kinase, lactate dehydrogenase, electrolytes), electrocardiograms, method of substance use, additional substance use, period of clinical observation, hospitalization status and mortality rates.

\section{Results}

Thirteen substance abuse admissions according to statement of patient her/himself or witnesses, were made to our department between March 2013-March 2015 period. Of these 13 admissions, 10 (77\%) were due to "Bonzai" use. The youngest patient was a 7-month-old baby whose mother found her chewing a herbal substance. Age of remaining patients ranged between 12 and 17 years. There were 3 female $(33.4 \%)$ and 6 male $(66.6 \%)$ patients. The most common complaint was faintness and tendency to sleep (89\%). One patient was admitted with palpitation. The most common clinical findings were changes in the state of consciousness (drowsiness, tendency to sleep, confusion, somnolence, disorganization) (89\%), muscle spasms / tremor $(33 \%)$, tachycardia $(22 \%)$, hypertension $(22 \%)$, mydriasis $(22 \%)$ and vertigo $(22 \%)$. Skin rash and perioral cyanosis were present in 1 patient, bradycardia in 1 patient, incessant laughing attacks and inability in speaking in 1 patient, sensation of thirst in 1 patient and decreased oxygen saturation in the 7-month-old patient. Blood sugar levels $(106-171 \mathrm{mg} / \mathrm{dl})$ in 8 patients and creatine kinase levels (200-290 $\mathrm{U} / \mathrm{L}$ ) in 4 subjects were found slightly higher in laboratory examinations.

Kidney and liver function tests, electrolytes and coagulation profile were normal in all patients. All patients had 14-15 points from Glasgow Coma Scale except 1 patient with 10 points. There were slight electrocardiogram changes in patients with tachycardia. Electrocardiograms were normal in the rest of patients. The most common way of substance use was in smoking form. One patient chewed the substance and one patient used the substance in the form of a tablet. All patients had history of previous "Bonzai" use, except the 7-month-old patient and the patient with palpitation. Additionally, the patient with palpitation complaint consumed 5 bottles of beer before using "Bonzai". Two patients required pediatric intensive care unit observation and 2 patients required hospitalized observation, while remaining patients were discharged after the observation in the emergency unit. The mean period of observation in the emergency unit was 21.8 (4-35) hours. The mean period of observation in hospitalized patients was 42 (24-72) hours. There was no death in the patient group. All patients except the 7-month-old patient received pediatric psychiatry consultation and all necessary guidance was made in terms of substance addiction and forensic reports were organized. Overall data of the patient group is seen in Table I.

\section{Discussion}

Worldwide use of SCs have increased in recent years. Parallel to this increase, frequency of previously unexpected complications and symptoms among these cases have also increased. Synthetic cannabinoids have become the most frequently used illegal substance worldwide with an estimated number of 160 million users 5 . As it is possible to make changes in their chemical composition, various combinations of SCs may arise. So, it is obvious that use of SCs will be a great problem ${ }^{1}$. The number of SCs detected by European Monitoring Centre of Drugs and Drug Addiction (EMCDDA) and Early Warning System (EWS) is increasing acutely. The first officially detected SC is JWH-018 substance, which was detected in 2008 in Germany. EMCDDA has reported that 9 SCs in 2009, 11 SCs in 2010, 23 SCs in 2011, 30 SCs in 2012, 29 SCs in 2013, and 30 SCs in 2014 were detected. A total number of 137 SCs were reported until February 2016 by ECMDDA ${ }^{6}$. Gurdal et al. ${ }^{4}$ investigated the contents of herbal substances that were captured by police in the Istanbul region and have found that 1,179 of 1,200 herbal substances $(98.3 \%)$ contained SCs. Use of SCs in Turkey is also increasing and is popular among adolescents as it is cheap and easily 
accessible $\mathrm{e}^{7,8}$. In the publications carried out in our country, it is reported that the substance is largely obtained from the street vendors called drug dealer 7,8 . There is no information about this issue in our retrospective study.

Their cannabis-like effects with stronger exhilarating effects than cannabis, their ease in obtaining and difficulty in detecting through toxicological screening methods made SCs popular among adolescents and young adults $^{9}$. The substance is highly lipophilic in a crystalline powder form originally. The lipophilic properties of the substance give good solubility in solvents such as methanol, ethanol, and acetone. SCs used in herbal products have low solubility in water, they are marketed after they are sprayed on some dried plants (mint, lemon balm, thyme, leaves of bonsai tree) and their smoke is inhaled ${ }^{1}$.

"Bonzai" is a product which is obtained by mixing SCs in various percentages ${ }^{7-10}$. It shows chemically similar structural features with delta 9-tetrahidrocannabiol (THC) which is the active ingredient of marijuana ${ }^{2}$. SCs reveal their effects through $\mathrm{CB} 1$ and $\mathrm{CB} 2$ receptors that are located in the central and peripheral nervous system ${ }^{1,3}$. Synthetic cannabinoids have direct agonistic effect on $\mathrm{CB} 1$ receptors and have maximum effect even at low doses. CB1 receptor affinities of SCs are higher than THC derivatives. Therefore, the size and frequency of their effects as well as the severity of their adverse effects are much greater ${ }^{2,10}$. Unlike THC, SC metabolites also have biological activities at various levels and duration of their action is longer ${ }^{3}$. Synthetic cannabinoids are 4-5 times more powerful than marijuana, and when these products were analyzed, it was found that SCs contain many chemical, stimulating, hallucinogenic substances ${ }^{11}$. There are several types of SCs and other substances can be found in unknown quantities in a package of product. These different combinations cause a wide variety of physical symptoms ${ }^{7}$.

Although SCs are usually smoked in the form of cigarette (pipe, through smoking or hookah), its use through evaporation, oral or rectal use are also reported ${ }^{5}$. Parenteral use of SCs has not been reported yet. The effect of SCs usually starts within a few minutes as they are absorbed from the lungs immediately after smoking and redistributed to the other organs such as brain.
However, after oral use, there can be a delay in the onset of action depending upon food intake, digestion activity and the changes in the first pass effect ${ }^{5,8}$. The lipophilic nature of SCs causes storage in the fatty tissue, showing a biphasic effect and the gradual elimination after their consumption ${ }^{5}$. The way that our patients inhale the substance was in the form of smoking. One of our patients consumed the substance in the form of oral tablet and also one patient chewed the plant. In the literature, it is reported that inhalation in the form of cigarette is the most common use of SCs in our country and in the whole world $7,8,12$. The infants' exposure to SC in different ways has begun to be reported in the literature. Thornton et al. ${ }^{13}$ reported the clinical process consisting coma and intubation of a 10-month-old patient after chewing the cigarette containing SC. Lavi et al. ${ }^{14}$ found SC in the urine of 3 infants presenting with encephalopathy and reported smoke exposure in one patient due to SC containing cigarette smoking of her elder sister very closely. The authors also reported that SC containing cigarette package of the baby-sitter of one patient was missing. The frequent use of SCs in the community will affect the infants indirectly. Our 7-month-old patient also chewed the SC substance that his mother uses. The patient admitted to the emergency department because the baby had tendency to sleep after 3 hours after chewing the substance. The patient was treated by nasal oxygen because of low blood oxygen saturation during the observation. The case was regarded as a case of neglected child and has been reported to the judicial authority and bureau of social services. Since then, the child's family has been monitored by the Ministry of Family and Social Policies.

After SC use, the symptoms related to all systems, especially including central nervous system and cardiovascular system can be seen ${ }^{1,3,12}$. Several symptoms such as agitation, anxiety, epileptic seizures, nausea, vomiting, drowsiness, confusion, slurred speech, dizziness, hallucinations, fever, sweating, conjunctival hyperemia, tachycardia, chest pain, hypertension and rarely hypotension have been reported ${ }^{1,7,10,12}$. The most frequent clinical symptoms detected in adolescents registered Texas Intoxication Center were reported as tachycardia (41.6\%), drowsiness/ lethargy $(24.3 \%)$, agitation/irritability $(16.4 \%)$, 


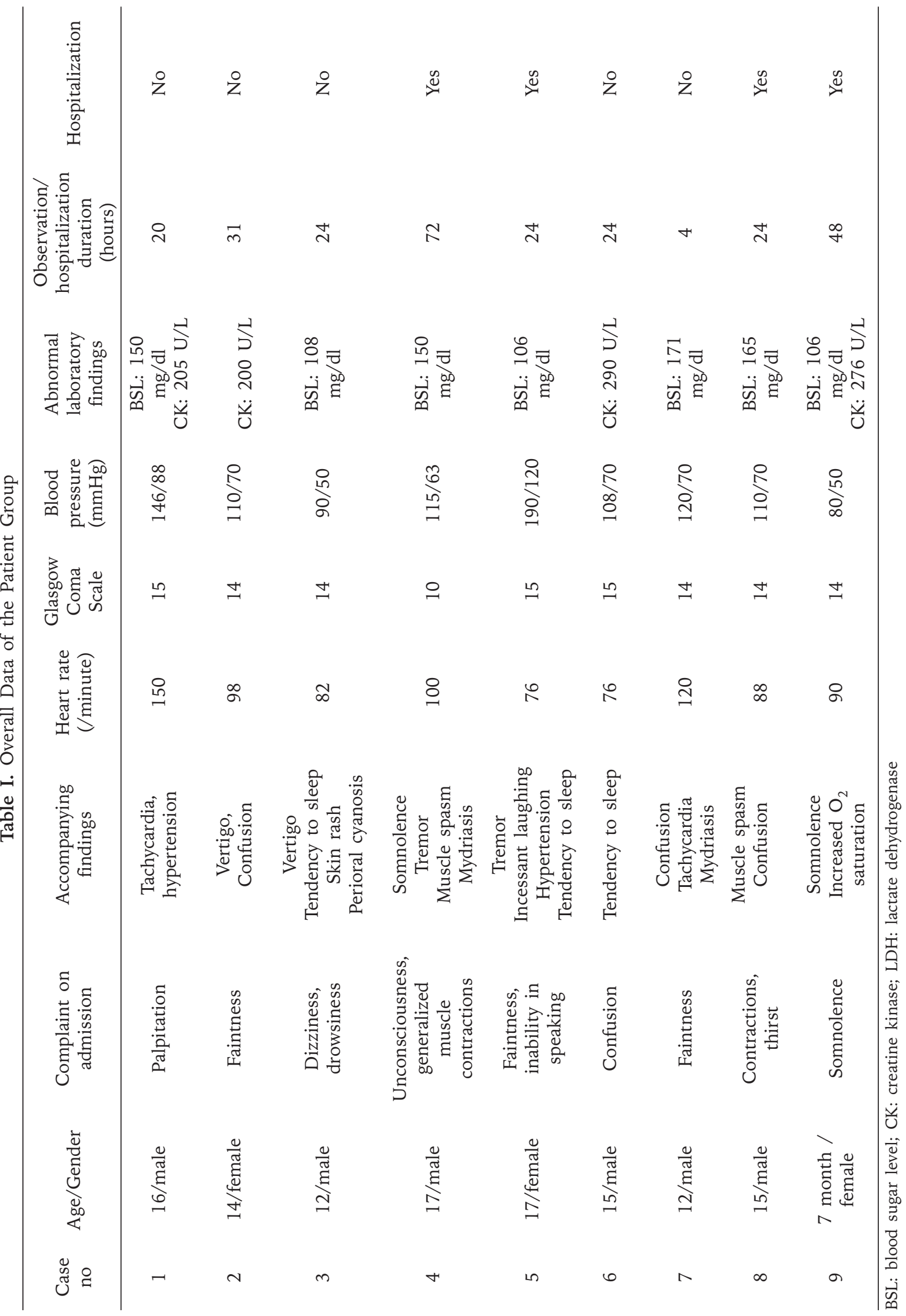


vomiting (13.1\%), and hallucinations (10.8\%). Nausea, confusion, hypertension, chest pain and dizziness were observed in less than $10 \%$ of subjects. In this study adults and adolescents were compared, drowsiness and lethargy in adolescents and agitation and irritability in adults were identified as more frequent symptoms ${ }^{15}$. Besli et al. ${ }^{7}$ from our country reported $75 \%$ altered level of consciousness and $31.2 \%$ syncope. Küçük et al. ${ }^{10}$ reported $13.39 \%$ fainting and unconsciousness with $25 \%$ sudden aggression and absurd movements in their study which included patients older than 15 years. The patients in our study were also admitted to our department with similar complaints like faintness and somnolence. All these data suggest increased frequency of alterations in level of consciousness among adolescents. Effects of SCs immediately starts as they are easily absorbed from the airway. They decrease intraocular pressure and cause conjunctival hyperemia ${ }^{5}$. Besli et al. ${ }^{7}$ have reported conjunctival hyperemia in a rate of $87.5 \%$ in adult patients. No conjunctival hyperemia has been detected in our patients. We suppose there was some failure in patient records about this fact in our retrospective study. Cardiovascular effects can be seen even with one cigarette containing SC and dose-dependent tachycardia and hypertension may develop. In chronic users, hypotension, bradycardia, and postural hypotension can be seen. Symptoms such as atrial fibrillation, ventricular tachycardia, acute myocardial infarction have also been reported ${ }^{5}$. Possible mechanisms of these effects are cardiac ischemia depending on increased heart rate, postural hypotension, decreased oxygenation due to the increasing carboxyhemoglobin levels especially coupled with smoking and catecholaminemediated proarrhythmia ${ }^{16}$. Ischemic stroke cases in young adults have been reported ${ }^{17}$. Besli et al. ${ }^{7}$ reported $37.5 \%$ tachycardia, 31.2 $\%$ bradycardia and $18.2 \%$ hypertension in their study. There were $22 \%$ tachycardia, $11 \%$ bradycardia and $22 \%$ hypertension in our cases. Harris et al. ${ }^{12}$ reported hypertension in all cases in their study concerning 6 patients. The authors also reported tachycardia in 5 patients. The small amount and the younger age of our cases may cause decreased rates against the literature in our study. There was no case with nausea and vomiting in our study. In contrast, various amounts of nausea and vomiting have been reported in the literature 7,15 . It has been reported that acute renal failure has been detected in the patients admitting with nausea, vomiting and flank pain. It is not clear whether acute tubular necrosis occurs with direct toxic effect or ischemia secondary to hypovolemia ${ }^{18,19}$.

The patients generally admit to the emergency departments with the symptoms of behavioral disorders (agitated behaviors, psychosis, anxiety) or acute critical illness. Acute critical illness involves seizures (prolonged seizures can lead to rhabdomyolysis and hyperthermia), acute renal failure, myocardial ischemia and infarction. Most mild intoxications are curable with only symptomatic treatment and usually there is no need to hospitalize the patient. The patients having serious symptoms like seizures, severe agitation or deterioration of mental status, arrhythmia and serious chest pain should be sent to the hospital for further examination ${ }^{20}$. Even though the most common cause of admission was alterations in level of consciousness, most of the patients in our study recovered quickly; only 4 cases required hospitalization. Correspondingly, the hospitalized cases also showed fast recovery and discharged after a short period of hospitalization.

In patients with SC use history or suspicion, blood glucose levels, electrolytes, liver and renal function tests, complete blood count and coagulation tests, cardiac markers, creatinine kinase level, urine drug screening tests are recommended $^{5}$. SCs make various metabolic changes such as hypocalcemia, hyperglycemia, acidosis, and increase of creatinine kinase levels ${ }^{7,11}$. In $89 \%$ of our patients the blood glucose levels and in $44 \%$ of them the creatinine kinase levels were found slightly elevated. Complete blood counts, coagulation tests, liver and renal function tests, electrolyte levels were normal in our patients. Besli et al. ${ }^{7}$ reported mild hyperglycemia in $60 \%$ and increased creatin kinase in $40 \%$ of cases. Liver and renal functions of the cases were normal in their study. Ergül et al. ${ }^{2}$ noticed elevated creatin kinase levels in all cases in their study. Serious cases of rhabdomyolysis with elevated creatin kinase levels after SCs use, have been reported from our country and 


\section{from the world 2,21 .}

Hypoglycemia, central nervous system infections, thyroid hyperactivity, head trauma and mental illnesses should be considered in differential diagnosis ${ }^{20}$. Clinicians should keep in mind that there could be serious cardiovascular, cerebrovascular, neurological, psychiatric, and renal effects ${ }^{20,22}$. Supportive treatment is often sufficient. To ensure the safety of airway, the control of agitation (benzodiazepines), inhibiting rhabdomyolysis (intravenous fluid), monitoring in terms of cerebral and cardiac ischemia are recommended $5,20,22$.

All patients in our study either have expressed using "Bonzai" themselves or the witnesses have told that they use "Bonzai", but the validation test has not been carried out. There may be clinical discrepancies between the patients worldwide because ingredients of SC containing substances may differ from each other in different locations and time periods. Probably more patients hiding their substance use admit to our pediatric emergency department with various symptoms. With the increase of awareness and information on this issue, we think that clinicians will more quickly recognize such patients.

\section{REFERENCES}

1. Artuç S, Doğan KH, Demirci Ş. Uyuşturucu maddelerde yeni trend: Sentetik Kannabinoidler. Adli Tıp Bülteni 2014; 19: 198-203.

2. Ergül DF, Ekemen S, Büyükkıdan Yelken B. Sentetik kannabinoid 'Bonzai' intoksikasyonu: Altı olgu serisi. Türk Anestezi ve Reanimasyon Dergisi 2015; 43: 347 351.

3. Kalyoncu ÖA, Ünlü B, Taştan U. Gençlerin tehlikeli oyunu: Sentetik kannabinoidler (Bonzai) üzerine bir gözden geçirme. Bağımlılık Dergisi 2014; 15: 150-155.

4. Gurdal F, Asirdizer M, Aker RG, et al. Review of detection frequency and type of synthetic cannabinoids in herbal compounds analyzed by Istanbul Narcotic Department of the Council of Forensic Medicine, Turkey. J Forensic Leg Med 2013; 20: 667-672.

5. Rella JG. Recreational cannabis use: Pleasures and pitfalls. Cleveland Clin J Med 2015; 82: 765-772.

6. http://www.emcdda.europa.eu/attachements.cfm/ att 212361 EN EMCDDA POD 2013 Synthetic\%20 cannabinoids.pdf. (Accessed: February 10, 2016).

7. Besli GE, Ikiz MA, Yildirim S, et al. Synthetic Cannabinoid Abuse in Adolescents: A Case Series. J Emerg Med 2015; 49: 644-650.
8. Bozkurt M, Umut G, Evren C, et al. Sentetik kannabinoid kullanımı nedeniyle polikliniğe başvuran hastaların klinik özellikleri ve laboratuvar sonuçları. Düșünen Adam: Psikiyatri ve Nörolojik Bilimler Dergisi 2014; 27: 328-334.

9. Hudson S.,Ramsey J, King L, et al. Use of highresolution accurate mass spectrometry to detect reported and previously unreported cannabinomimetics in "herbal high" products, J Anal Toxicol 2010; 34: 252-260.

10. Küçük E, Küçük İ, Kirazaldı YY. Acil serviste yeni bir tehlike: Sentetik kannabinoidler (Bonzai, Jameika). Genel Tip Dergisi 2015; 25: 18-22.

11. Seely KA, Patton AL, Moran CL, et al. Forensic investigation of K2, Spice, and "bath salt" commercial preparations: A three-year study of new designer drug products containing synthetic cannabinoid, stimulant, and hallucinogenic compounds. Forensic Sci Int 2013; 233: 416-422.

12. Harris CR, Brown A. Synthetic cannabinoid intoxication: a case series and review. J Emerg Med 2013; 44: 360336.

13. Thornton SL, Akpunonu P, Glauner K, et al. Unintentional pediatric exposure to synthetic cannabinoid (AB-PINACA) resulting in coma and intubation. Ann Emerg Med 2015; 66: 343-344.

14. Lavi E, Rekhtman D, Berkun Y, et al. Sudden onset unexplained encephalopathy in infants: think of cannabis intoxication. Eur J Pediatr 2016; 175: 417 420.

15. Forrester MB. Adolescent synthetic cannabinoid exposures reported to Texas poison centers. Pediatr Emerg Care 2012; 28: 985-989.

16. Aryana A, Williams MA. Marijuana as a trigger of cardiovascular events: speculation or scientific certainty? Int J Cardiol 2007; 118: 141-144.

17. Wolff V, Lauer V, Rouyer O, et al. Cannabis use, ischemic stroke, and multifocal intracranial vasoconstriction: a prospective study in 48 consecutive young patients. Stroke 2011; 42: 1778-1780.

18. Centers for Disease Control and Prevention (CDC). Acute kidney injury associated with synthetic cannabinoid use - multiple states, 2012. MMWR Morb Mortal Wkly Rep 2013; 62: 939-948.

19. Buser GL, Gerona RR, Horowitz BZ, et al. Acute kidney injury associated with smoking synthetic cannabinoid. Clin Toxicol (Phila) 2014; 52: 664-673.

20. Tait RJ, Caldicott D, Mountain D, et al. A systematic review of adverse events arising from the use of synthetic cannabinoids and their associated treatment. Clin Toxicol (Phila) 2016; 54: 1-13.

21. Duran D, Delgado LL, de la Parra-Pellot DM, et al. Psychosis and severe rhabdomyolysis associated with synthetic cannabinoid use: a case report. Clin Schizophr Relat Psychoses 2015; 4: 205-208.

22. Roberts JR. Synthetic cannabinoids: treating toxicity. Emerg Med News 2015; 37: 12-14. 